\title{
Risk factors for pregnancy-related clinical outcome in myasthenia gravis: a systemic review and meta-analysis
}

\author{
Manqiqige Su ${ }^{1,2 \dagger}$, Xiaoqing Liu ${ }^{3+}$, Liang Wang ${ }^{1,2}$, Jie Song ${ }^{1,2}$, Zhirui Zhou ${ }^{4}$, Sushan Luo ${ }^{1,2^{*}}$ (i) and \\ Chongbo Zhao ${ }^{1,2^{*}}$
}

\begin{abstract}
Objective: Myasthenia gravis (MG) is an autoimmune disorder that frequently affects females at reproductive age. Herein, we aimed to assess the associations of clinical factors with pregnancy-related outcome in MG.

Methods: We searched PubMed and EMBASE for case-control and cohort studies that reported the MG status during or after pregnancy and relevant clinical variables. The data was extracted in proportions and odds ratios (ORs) with 95\% confidence intervals (Cls) in subsequent meta-analysis.

Results: Fifteen eligible articles reporting on 734 pregnancies with 193 worsening and 51 improved episodes were included out of 1765 records. The estimated worsening proportions in total, antepartum and postpartum periods

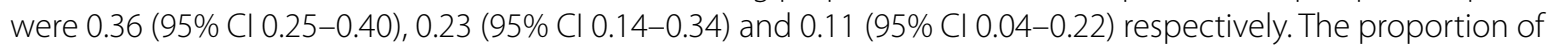
pregnancy-related improvement in enrolled patients was 0.28 (95\% Cl $0.17-0.40)$, with 0.07 (95\% Cl 0.00-0.28) during pregnancy and 0.14 (95\% Cl 0.02-0.34) after pregnancy. No significant associations were disclosed between the clinical factors and MG worsening. Thymectomy before delivery is a strong predictor for MG improvement in postpartum period (OR 4.85, 95\% Cl 1.88-12.50, $\mathrm{p}=0.001$ ).

Conclusion: The total proportion of pregnancy-related MG worsening and improvement in MG was 0.36 ( $95 \% \mathrm{Cl}$ $0.25-0.40)$ and 0.28 (95\% Cl 0.17-0.40), respectively. Thymectomy before the delivery may aid in clinical improvements associated with pregnancy. Future prospective cohort studies are required to determine more relevant factors.
\end{abstract}

Keywords: Myasthenia gravis, Pregnancy, Worsening, Risk factor, Meta-analysis

\section{Introduction}

Myasthenia gravis (MG) is an autoimmune disorder in neuromuscular junction with a prevalence ranged from 15 to 179 per million person [1, 2]. MG has a bimodal age pattern of incidence, with a peak in female individuals under age 40 , that overlaps with the reproductive age $[3,4]$. During the pregnancy period with maternal

\footnotetext{
*Correspondence: luosushan@fudan.edu.cn; zhao_chongbo@fudan.edu.cn ${ }^{\dagger}$ Manqiqige Su and Xiaoqing Liu are co-first authors

${ }^{1}$ Huashan Rare Disease Center, Department of Neurology, Huashan Hospital, Fudan University, 200040 Shanghai, China

Full list of author information is available at the end of the article
}

physiological adaption and obstetric complications, female patients with autoimmune diseases may be more vulnerable to clinical and life events [5-9]. Characterized by fluctuating weakness in ocular, limb and bulbar muscle, rapid clinical worsening can be a serious life-threatening condition for both mothers and fetus. The optimal managements of MG during and after pregnancy require special attentions and individualized consideration.

The overall proportion for clinical worsening ranged from 10 to $90 \%$ in MG patients with pregnancy, with varied distributions in 1st, 2nd, 3rd trimester or puerperium [10-13]. A short disease duration and advanced clinical

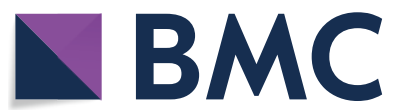

(c) The Author(s) 2022. Open Access This article is licensed under a Creative Commons Attribution 4.0 International License, which permits use, sharing, adaptation, distribution and reproduction in any medium or format, as long as you give appropriate credit to the original author(s) and the source, provide a link to the Creative Commons licence, and indicate if changes were made. The images or other third party material in this article are included in the article's Creative Commons licence, unless indicated otherwise in a credit line to the material. If material is not included in the article's Creative Commons licence and your intended use is not permitted by statutory regulation or exceeds the permitted use, you will need to obtain permission directly from the copyright holder. To view a copy of this licence, visit http://creativecommons.org/licenses/by/4.0/. The Creative Commons Public Domain Dedication waiver (http://creativeco mmons.org/publicdomain/zero/1.0/) applies to the data made available in this article, unless otherwise stated in a credit line to the data. 
severity were associated with a profound probability for MG worsening [11-14]. However, most studies did not identify any significant correlations between duration, age at pregnancy, serological tests, delivery mode, or therapies and clinical worsening. Remarkably, the effects of thymectomy on the clinical outcome during or after pregnancy are still controversial $[11,15,16]$.

To date, there is no comprehensive meta-analysis on risk or protective factors for the course of MG during/ after pregnancy. Given the current inconclusive results, our review mainly aims to assess the clinical status in female MG patients during or after pregnancy, and explore the associations between the clinical factors with MG exacerbation or improvement. Herein, we conducted a systemic review and meta-analysis to estimate the overall proportion for MG worsening related with pregnancy and to identify risk factors that predict pregnancy-related clinical outcome.

\section{Method}

The systematic review was reported according to the PRISMA (The Preferred Reporting Items for Systematic reviews and Meta-Analysis) statement [17]. Ethical permission was not required by the author's institution for systematic reviews of available primary literature. The protocol was registered with PROSPERO, the international prospective register of systematic review (CRD42021269938).

\section{Search strategy}

To identify all cases who had an episode of MG worsening and improvement during/after pregnancy, we searched PubMed and Embase with a last update on 12 August, 2021 with search terms including "myasthenia", "myasthenia gravis", "pregnancy", "pregnant", "labor", "labour", "maternal" and "gestation". Reference lists of articles were also examined, and full-text papers were accessed and analyzed by all authors.

\section{Inclusion criteria}

Studies eligible for the systemic review and meta-analysis met the pre-defined criteria: (1) case-control or cohort studies; (2) MG was diagnosed before or during pregnancy with supportive evidence from clinical, neurophysiological or serological testing; (3) Full description of MG status before/during/after pregnancy can be clearly identified; (4) a publication written in English to permit easy access to the source information of all included articles.

\section{Exclusion criteria}

Articles were excluded based on the following exclusion criteria: (1) less than 5 cases included; (2) publication out of scope such as single case reports, case series, reviews, conference abstracts, commentary editorials or letters that reported no new data.

\section{Data extraction and quality assessment}

Included studies were scrutinized for potential clinical data of myasthenia outcomes related to pregnancy. For the initial screening, the studies were independently evaluated by two authors (MS and XL) for inclusion. The conflicts if any were resolved after mutual discussions with the third author (SL). When studies included the overlapping data from the same patient sources, data from the largest cohort will be retained for further analysis. The following data were also extracted in a standard form from each study: name of the first author, year of publication, country, study design, number of patients, number of pregnancies, number of miscarriages, times of MG worsening and improvement, definition of worsening and improvement (Additional file 1). Other relevant clinical details on worsening and improvement were further screened to calculate the proportion/OR and 95\% CI if available. If the OR is greater than 1 and $p$ value is less than 0.05 , then this clinical factor and MG worsening/ improvements are considered to be significantly associated. Quality of evidence was accessed using the Newcastle Ottawa scale (Additional file 2), in which higher scores indicated higher quality.

\section{Primary and secondary outcomes}

The primary outcomes were defined as clinical changes indicating MG worsening related to pregnancy. According to the previous studies $[11,12,15,18-20]$ and existing guidelines [21], the worsening of myasthenia gravis related to pregnancy was determined if: (1) newly involved muscle domain or persistent exacerbation in original involved muscle at the same drug dosage; (2) increased dosages of medications or requirement for adding a new drug to control symptoms; (3) higher stage according to correlated clinical classifications/ scoring systems; (4) clearly described as "exacerbation" or "worsening" in original articles. We evaluated the primary outcomes using the odds ratios (ORs) by possible risk factors, and estimated the pool estimates of worsening proportions during every trimester of pregnancy (0-3 months, 4-6 months and 7-9 months), and after delivery/abortion (0-6 months).

The secondary outcomes were defined as clinical changes indicating MG improvement related to pregnancy. MG improvement was defined as: (1) improvement of clinical myasthenic manifestations or a significant reduction in MG medications than those they received before pregnancy; (2) clearly described as "improved" or "better" in original articles (Additional file 3). 


\section{Statistical analysis}

Proportions and ORs were extracted and calculated based on raw data from primary studies. Freeman-Turkey double arcsine transformation method was used to calculate the combined proportion of worsening in different and the $95 \%$ confidence interval (CI). Q test and $\mathrm{I}^{2}$ statistics were used in detection for heterogeneity. The fixed effect analysis was applied if there exists heterogeneity $\left(\mathrm{p}>0.10\right.$ and $\left.\mathrm{I}^{2}<50 \%\right)$, otherwise the random effects analysis was used. Statistical significance was set at $\mathrm{p}<0.05$ with a 95\% CI. Statistical tests of Funnel plots were conducted to visualize the publication bias $(\mathrm{N}>10)$ and Egger's test was used to assess funnel plot asymmetry. Trim and fill methods were then used to detect symmetry. To evaluate the stability of results and explain the possible source of heterogeneity $(\mathrm{N}>2)$, sensitivity analysis for potential risk factors was performed using the leave-oneout analysis by omitting one study at a time. A quantitative synthesis of the collective findings was performed through R language (v. 4.1.1) (http://www.r-project.org) with the meta package [22].

\section{Result}

\section{Studies retrieved and characteristics}

Various database searches resulted in 1765 records, of which 386 had to be excluded on the basis of titles or abstracts and 1379 were identified for full-text review. Finally, we identified 15 cohort studies that fulfilled the inclusion criteria and included in qualitive synthesis (Fig. 1) [10-16, 18, 20, 23-28], and there existed no overlapping data among these studies. The analysis enrolled 734 pregnancies in total from 574 pregnant MG patients, among who 194 pregnancies correlated with worsening and 51 pregnancies correlated with improvement.

\section{Primary outcome}

The pooled estimate of overall MG worsening proportion is 0.36 (95\% CI $0.25-0.49$ ) (Fig. 2), with 0.23 (95\% CI 0.14-0.34) during pregnancy and 0.11 (95\% CI 0.04$0.22)$ after pregnancy $(\mathrm{N}=15)$. Among them, 9 studies had provided detailed proportions of worsening in each trimester from a total of 500 pregnancies and 143 episodes of MG worsening. MG worsening proportions in each trimester were then evaluated as: 0.04 in first trimester (95\% CI 0.01-0.10), 0.04 in second trimester (95\% CI $0.00-0.10)$ and 0.09 in third trimester $(95 \% \mathrm{CI}$ $0.02-0.19)$.

After excluding 14 factors which have very limited data for evaluation (Additional file 4), we included ten factors in the meta-analysis as potential risk factors for MG worsening related to pregnancy. These factors included thymectomy before/during pregnancy (OR $0.55,95 \%$ CI $0.27-1.10)(\mathrm{N}=7)$, steroids use before pregnancy (OR $0.64,95 \%$ CI $0.26-1.59)(\mathrm{N}=3)$, preterm delivery (OR 3.06 95\% CI $0.97-9.69)(\mathrm{N}=6)$, parity history (OR 2.14, 95\% CI $0.39-11.80)(\mathrm{N}=2)$, ocular MG (OR 0.54, 95\% CI 0.07-4.41) $(\mathrm{N}=3)$, delivery with forceps (OR $0.41,95 \%$ CI $0.05-3.31)(\mathrm{N}=2)$, complete remission before pregnancy (OR 1.04, 95\%
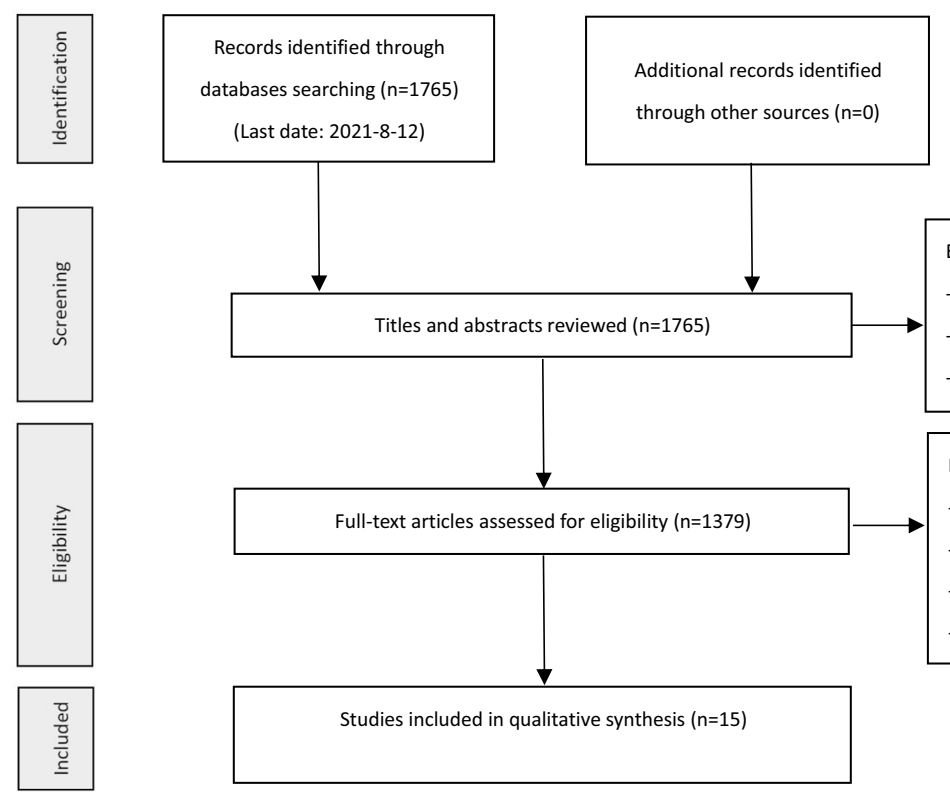

Excluded $=386$

Duplicates ( $n=250)$

Review and conference abstract ( $n=124)$

- Not in English ( $n=12$ )

Excluded $=1364$

No MG with pregnancy $(n=1289)$

Without state of MG ( $n=14)$

Only abstract $(\mathrm{N}=42)$

Cases reported less than $5(n=19)$

Fig. 1 PRISMA (The Preferred Reporting Items for Systematic reviews and Meta-Analyses) flow chart of study selection 


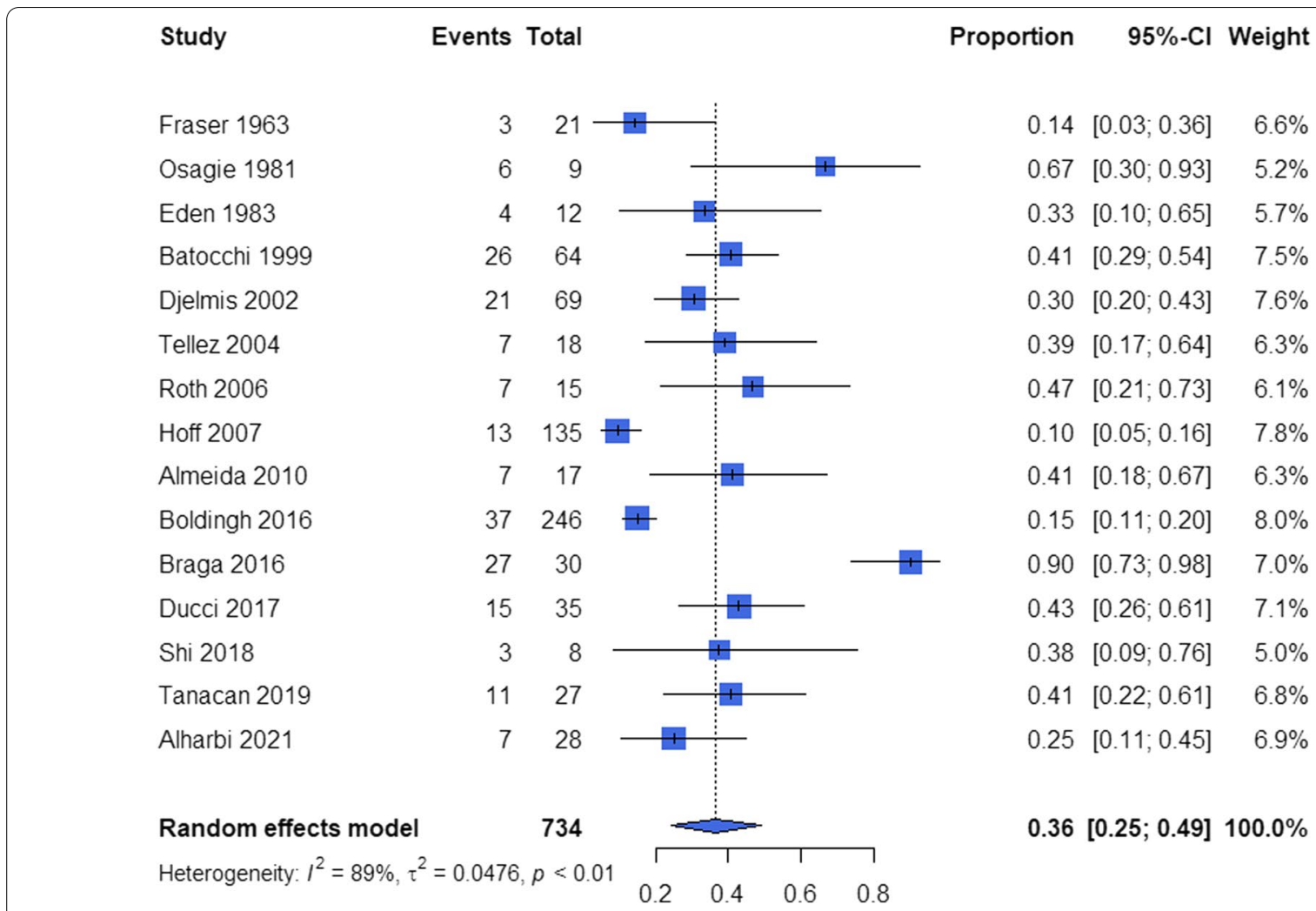

Fig. 2 The pooled total proportions of worsening associated with pregnancy. Events: number of pregnancies with worsening associated with pregnancy. Total: total number of pregnancies

CI 0.49-2.19) $(\mathrm{N}=5)$, caesarean section (OR 0.39, 95\% CI 0.05-3.21) $(\mathrm{N}=4)$, anticholinesterase treatments before pregnancy (OR 1.00 95\% CI 0.50-1.98) ( $\mathrm{N}=4)$, and AChR Antibody-positive (OR 1.56 95\% CI 0.1219.50) $(\mathrm{N}=2)$. However, none of these factors showed significant associations with MG worsening (Fig. 3).

\section{Secondary outcome}

The pooled proportion of pregnancy-related improved MG was 0.28 (95\% CI 0.17-0.40) $(\mathrm{N}=8)$ (Fig. 4), with 0.07 (95\% CI 0.00-0.28) $(\mathrm{N}=5)$ during pregnancy and 0.14 (95\% CI 0.02-0.34) $(\mathrm{N}=5)$ after pregnancy. In the meta-analysis for improved MG status during/after pregnancy, we found that the patients with thymectomy before/during pregnancy (OR 4.05, 95\% CI $1.60-10.24, \mathrm{p}=0.003)(\mathrm{N}=6)$ has a high probability to achieve MG improvement (Fig. 5), whereas term delivery didn't contribute in the improvement (OR $1.08,95 \%$ CI $0.14-8.39)(\mathrm{N}=2)$ in a significant level. Other potential risk factors could not be pooled due to the limited data retrieved (Additional file 5).

\section{Publication bias in estimating the reported worsening episodes}

As publication bias was detected by funnel plot and Egger's test in the total proportion of pregnancy-related worsening $(p=0.009, N=15)$, the trim and fill method was applied to analyze the publication bias following original funnel plots (Additional file 6). In comparison to a previous proportion of 0.36 (95\% CI 0.24-0.49), the adjusted estimated proportion after adding seven additional studies was 0.19 (95\% CI 0.09-0.30), which indicated a publication bias. Publication bias also existed in the estimates of worsening proportions during pregnancy $(\mathrm{p}=0.001, \mathrm{~N}=15)$, while the $\mathrm{p}$-value of Egger's test for the pooled proportion of worsening after pregnancy was $0.44(\mathrm{~N}=15)$. Sensitivity analysis did not reveal any significant changes.

\section{Discussion}

MG is a chronic autoimmune disease of bimodal onset age with a peak occurring in young women at reproductive period. Previous studies mainly focused on the 


\begin{tabular}{|c|c|c|c|}
\hline Factors & OR and $95 \% \mathrm{Cl}$ & & $P$ value \\
\hline \multicolumn{4}{|l|}{ MG features } \\
\hline AChR-Ab+ (vs. AChR-Ab-) & $1.56[0.12,19.50]$ & $C=-1$ & 0.730 \\
\hline Ocular MG (vs. nonocular MG) & $0.54[0.07,4.41]$ & $\rightarrow-$ & 0.568 \\
\hline Thymectomy (vs. nonthymectomy) & $0.55[0.27,1.10]$ & - & 0.091 \\
\hline Ever use steriods (vs. no steriods) & $0.64[0.26,1.59]$ & -1 & 0.335 \\
\hline Use anticholinesterase drug (vs. no anticholinesterase drug) & $1.00[0.50,1.98]$ & -1 & 0.997 \\
\hline Complete remission (vs. Not CR) & $1.04[0.49,2.19]$ & $\rightarrow-$ & 0.918 \\
\hline \multicolumn{4}{|l|}{ Obsteric features } \\
\hline Parity $=0$ (vs. parity $>0$ ) & $2.14[0.39,11.80]$ & $\rightarrow$ & 0.383 \\
\hline Preterm (vs. term) & $3.06[0.97,9.69]$ & & 0.057 \\
\hline Forcep (vs. no forcep) & $0.41[0.05,3.31]$ & - & 0.399 \\
\hline \multirow[t]{2}{*}{ Caesarean section (vs. no caesarean section) } & $0.39[0.05,3.21]$ & $\rightarrow-1$ & 0.383 \\
\hline & & $\begin{array}{llllllllllll} & 1 & 1 & 1 & 1 & 1 & 1 & 1 & 1 & 1 \\
0 & 1 & 2 & 3 & 4 & 5 & 6 & 7 & 8 & 9\end{array}$ & \\
\hline
\end{tabular}

Fig. 3 Forest plots of association between clinical factors and worsening of MG status in odds ratio. Ten risk factors were extracted and there was no significant difference in ORs for worsening

\section{Study}

Fraser 1963

Osagie 1981

Batocchi 1999

Tellez 2004

Roth 2006

Ducci 2017

Shi 2018

Tanacan 2019

Random effects model

Heterogeneity: $I^{2}=62 \%, \tau^{2}=0.0172, p=0.01$

\section{Events Total}

1264

218

215

935

38

$7 \quad 27$

197

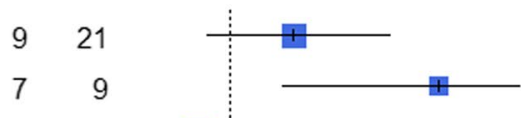

Fig. 4 The pooled total proportions of MG improvement associated with pregnancy. Events: number of pregnancies with improved associated pregnancy. Total: total number of pregnancies

\section{Proportion $\quad 95 \%-\mathrm{Cl}$ Weight}

$\begin{array}{rrr}0.43[0.22 ; 0.66] & 12.9 \% \\ 0.78[0.40 ; 0.97] & 8.6 \% \\ 0.19 & {[0.10 ; 0.30]} & 17.7 \% \\ 0.11 & {[0.01 ; 0.35]} & 12.1 \% \\ 0.13[0.02 ; 0.40] & 11.2 \% \\ 0.26[0.12 ; 0.43] & 15.4 \% \\ 0.38[0.09 ; 0.76] & 8.0 \% \\ 0.26[0.11 ; 0.46] & 14.2 \%\end{array}$

$0.28[0.17 ; 0.40] 100.0 \%$ impact of muscle weakness in delivery term or the incidence of neonatal MG [13, 16, 26, 28-31], whereas only a few retrospective cohort studies have attempted to assess the factors associated with MG worsening or improvement during or after pregnancy.

To the best of our knowledge, this is the first metaanalysis to explore the risk factors for predicting the 


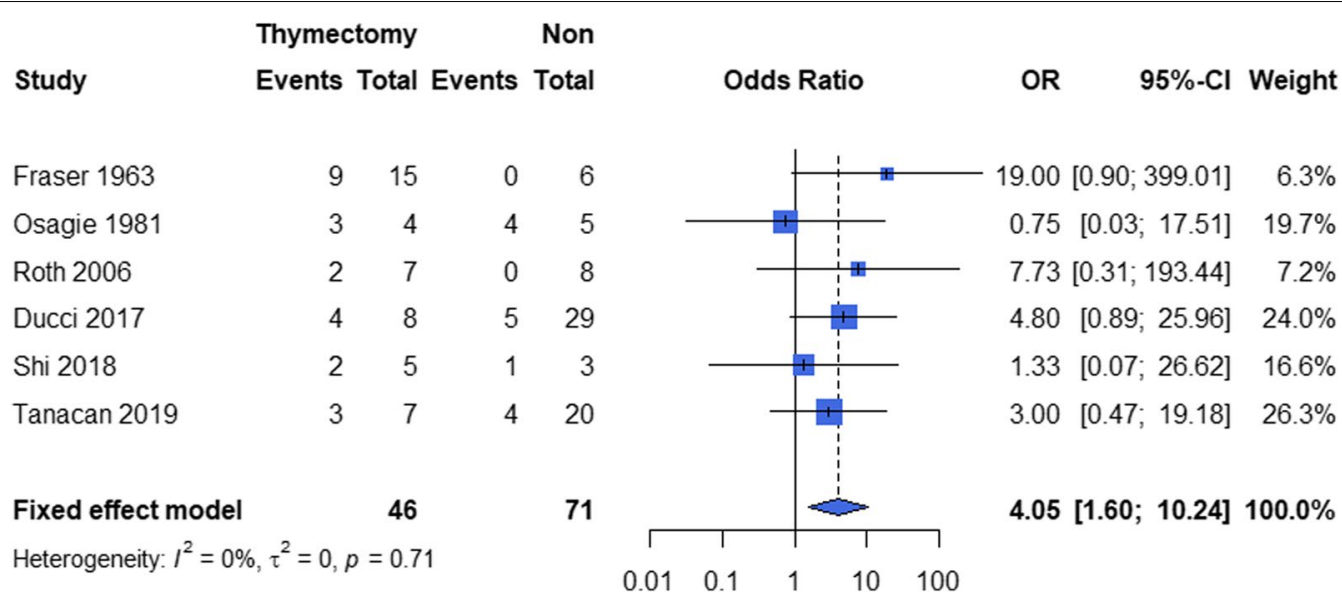

Fig. 5 Forest plot of association between thymectomy during/after pregnancy and improvement of MG status. Events: number of pregnancies with improved associated pregnancy. Total: total number of pregnancies

MG worsening for patients in pregnancy. Our metaanalysis revealed that the estimated proportion for MG worsening and improvement in patients during or after pregnancy is 0.36 (95\% CI $0.25-0.49)$ and 0.28 (95\% CI 0.17-0.40) respectively. From the nine studies entered the final analysis for preferential trimester, a slightly elevated worsening proportion during the third trimester was observed $(0.09,95 \%$ CI $0.02-0.19)$.

During and after pregnancy, distinct hormones with different concentrations may influence the immune network for MG pathogenesis in bidirectional modulation effect. In comparison to healthy controls, MG patients with anti- AChR/MuSK antibodies had low levels of galactosylated IgG2 [32]. In contrast, galactosylation and sialylation of immunoglobulin G1 and G2 increase during pregnancy and reach maximum levels in the third trimester and decrease directly in postpartum period [33]. This augmentation in IgG glycan changes has been proven to be regulated by estradiol via the overexpression of RUNX3 [34]. Regulatory B cells (Bregs) suppress pro-inflammatory responses via interleukin 10 (IL-10), as Bregs are largely expanded by the stimulation of estrogens via the PD-1/PD-L1 pathway from early pregnancy $[35,36]$. However, the pathogenic autoreactive B cells were reported to be boosted by Estrogens in the mice model of experimental autoimmune myasthenia gravis (EOMG) [37]. Progesterone, one of the most abundant hormones during pregnancy, may inhibit the formation of interleukin-17 (IL-17) producing Th17 cells and increase the frequency of regulatory $\mathrm{T}$ cells (Tregs) [38, 39]. Other potential mechanism included an inhibitory effect of alpha-fetoprotein on the binding of autoantibody to the AChR in MG patients [40].
As one of the mainstays in the treatments of myasthenia gravis, thymectomy has been accepted as a beneficial and effective treatment that is recommended for all patients concurrence with thymoma or refractory generalized MG with positive AChR antibodies [41-43]. For MG patients who are preparing or undergoing pregnancy, one of the most critical clinical decisions is the timing, safety and benefits of thymectomy. It has been reported that the incidence of neonatal MG was much lower if the mother had thymectomy before delivery $(\mathrm{p}=0.03)$ [16]. Our meta-analysis showed concordant results that thymectomy before/during pregnancy appeared to be strong determinant of improved outcomes (OR 4.85, 95\% CI 1.88-12.50, $\mathrm{p}=0.001$ ) and show a decreased tendency for the worsening (OR $0.55,95 \%$ CI $0.27-1.10, \mathrm{p}=0.09$ ), which can provide possible evidences for the recommendation of thymectomy for maternal MG. From an immunological point of view, thymectomy works in eliminating diversified and expanded $B$ cells in the germinal centers thus reducing the load for fetal AChR in thymus [44]. The efficacy of thymectomy on pursuing a better prognosis of pregnancy-related myasthenia gravis can be further explored in the future, especially for the clinical outcomes in the fertile MG patients with or without thymectomy.

There are several limitations that exist in our review. As noted already, the publication bias existed in our analysis, as there was a lack of high-qualified investigations in this field such as randomized trials and longitudinal prospective cohort studies. As the objectives and methods were heterogeneous in enrolled studies, the meta-analysis was performed across different designs, various definitions for MG worsening. There was a limitation of results as we could only provide 
overestimation of results as many concerned factors could not be analyzed. Future prospective cohort studies are anticipated to explore the optimal managements in controlling myasthenia gravis during or after pregnancies.

\section{Conclusion}

The MG worsening in relation to pregnancy was still unpredictable, which could occur in every period during/ after pregnancy. Thymectomy before delivery did not significantly decreased the risk of worsening but was found to improve the prognosis. For the better management of MG around pregnancy, thymectomy can be recommended to pursue a better short-term prognosis.

\section{Abbreviations}

MG: Myasthenia gravis; AChR: Acetylcholine receptor; MuSK: Muscle-specific kinase; OR: Odds ratio; Cl: Credibility interval; MOOSE: Meta-analysis of Observational Studies in Epidemiology; EOMG: Experimental autoimmune myasthenia gravis; RNS: Repetitive nerve stimulation; Ab: Antibody; CR: Complete remission.

\section{Supplementary Information}

The online version contains supplementary material available at https://doi. org/10.1186/s13023-022-02205-z.

Additional file 1. Characteristics of individuals from included studies except case reports.

Additional file 2. Newcastle-Ottawa scale for assessing the quality of the included studies in meta-analysis

Additional file 3. Myasthenia gravis status scale and definitions.

Additional file 4. Details of risk factors for worsening not included in the meta-analysis (single data or without original data).

Additional file 5. Details of clinical factors for improvement mot included in the meta-analysis (single data or without original data).

Additional file 6. Funnel plots of the meta-analysis before and after applying the trim-and-fill method.

\section{Acknowledgements}

We want to thank the support from Neuromuscular Research Group in Huashan hospital, Fudan University. We also thank Won Kyung Lee, MBBS, Zhongshan hospital, Shanghai Medical College of Fudan University for assisting with the editing.

\section{Authors' contributions}

LS and MS conceived and designed the study. MS and XL selected the articles and cross-checked the data. MS, ZZ and LW contributed to the statistical analysis. MS wrote the first draft of the manuscript. SL, ZZ, XL, JS and CZ contributed to the writing of the final version of the manuscript. All authors read and approved the final manuscript.

\section{Funding}

This work was supported by financial grants from the National Natural Science Foundation of China (Nos. 81870988 and 82071410), and Shanghai Municipal Science and Technology Major Project (No. 2018SHZDZX01) and ZJLab.

\section{Availability of data and materials}

Datasets supporting conclusions of this article are included within the article.

\section{Declarations}

\section{Ethics approval and consent to participate}

This study was conducted in accordance with the ethical standards established in the 1964 Declaration of Helsinki and was approved by the Medical Ethics Committee of Huashan Hospital affiliated to Fudan University (2019441). We were exempted from obtaining informed consent because this was a secondary analysis of previously published studies.

\section{Consent for publication}

Not applicable.

\section{Competing interests}

We declare no competing interests.

\section{Author details}

${ }^{1}$ Huashan Rare Disease Center, Department of Neurology, Huashan Hospital, Fudan University, 200040 Shanghai, China. ${ }^{2}$ National Center for Neurological Disorders, Shanghai 200040, China. ${ }^{3}$ Inner Mongolia Medical University, 010110 Inner Mongolia, China. ${ }^{4}$ Radiation Oncology Center, Huashan Hospital, Fudan University, Shanghai 200040, China.

Received: 8 December 2021 Accepted: 6 February 2022

Published online: 16 February 2022

\section{References}

1. Carr AS, Cardwell CR, McCarron PO, McConville J. A systematic review of population based epidemiological studies in myasthenia gravis. BMC Neurol. 2010;10:46

2. Chen J, Tian DC, Zhang C, Li Z, Zhai Y, Xiu Y, et al. Incidence, mortality, and economic burden of myasthenia gravis in China: a nationwide population-based study. Lancet Reg Health West Pac. 2020;5:100063.

3. Grob D, Brunner N, Namba T, Pagala M. Lifetime course of myasthenia gravis. Muscle Nerve. 2008;37(2):141-9.

4. Andersen JB, Heldal AT, Engeland A, Gilhus NE. Myasthenia gravis epidemiology in a national cohort; combining multiple disease registries. Acta Neurol Scand Suppl. 2014;198:26-31.

5. Ferrero S, Pretta S, Nicoletti A, Petrera P, Ragni N. Myasthenia gravis: management issues during pregnancy. Eur J Obstet Gynecol Reprod Biol. 2005;121(2):129-38

6. Malaiyandi D, James E, Peglar L, Karim N, Henkel N, Guilliams K. Neurocritical care of the pregnant patient. Curr Treat Options Neurol. 2021;23(7):22.

7. Graham JJ, Longhi MS, Heneghan MA. T helper cell immunity in pregnancy and influence on autoimmune disease progression. J Autoimmun. 2021;121:102651.

8. Berrih-Aknin S, Le Panse R. Myasthenia gravis: a comprehensive review of immune dysregulation and etiological mechanisms. J Autoimmun. 2014:52:90-100.

9. Khashan AS, Kenny LC, Laursen TM, Mahmood U, Mortensen PB, Henriksen TB, et al. Pregnancy and the risk of autoimmune disease. PLOS ONE. 2011;6(5):e19658.

10. Boldingh MI, Maniaol AH, Brunborg C, Weedon-Fekjær H, Verschuuren JJ, Tallaksen CM. Increased risk for clinical onset of myasthenia gravis during the postpartum period. Neurology. 2016;87(20):2139-45.

11. Braga AC, Pinto C, Santos E, Braga J. Myasthenia gravis in pregnancy: experience of a portuguese center. Muscle Nerve. 2016:54(4):715-20.

12. Ducci RD, Lorenzoni PJ, Kay CS, Werneck LC, Scola RH. Clinical followup of pregnancy in myasthenia gravis patients. Neuromuscul Disord. 2017:27(4):352-7.

13. Djelmis J, Sostarko M, Mayer D, Ivanisevic M. Myasthenia gravis in pregnancy: report on 69 cases. Eur J Obstet Gynecol Reprod Biol. 2002;104(1):21-5.

14. Alharbi M, Menon D, Barnett C, Katzberg H, Sermer M, Bril V. Myasthenia gravis and pregnancy: Toronto specialty center experience. Can J Neurol Sci. 2021;48(767):771.

15. Roth TC, Raths J, Carboni G, Rosler K, Schmid RA. Effect of pregnancy and birth on the course of myasthenia gravis before or after transsternal radical thymectomy. Eur J Cardiothorac Surg. 2006;29(2):231-5. 
16. Hoff JM, Daltveit AK, Gilhus NE. Myasthenia gravis in pregnancy and birth: identifying risk factors, optimising care. Eur J Neurol. 2007;14(1):38-43.

17. Page MJ, McKenzie JE, Bossuyt PM, Boutron I, Hoffmann TC, Mulrow CD, et al. The PRISMA 2020 statement: an updated guideline for reporting systematic reviews. BMJ. 2021;372:n71.

18. Téllez-Zenteno JF, Hernández-Ronquillo L, Salinas V, Estanol B, da Silva O. Myasthenia gravis and pregnancy: clinical implications and neonatal outcome. BMC Musculoskelet Disord. 2004;5:42.

19. Santos E, Braga A, Gabriel D, Duarte S, Martins da Silva A, Matos I, et al. MuSK myasthenia gravis and pregnancy. Neuromuscul Disord. 2018;28(2):150-3.

20. Tanacan A, Fadiloglu E, Ozten G, Gunes AC, Orgul G, Beksac MS. Myasthenia gravis and pregnancy: retrospective evaluation of 27 pregnancies in a tertiary center and comparison with previous studies. Ir J Med Sci. 2019;188(4):1261-7.

21. Jaretzki A 3rd, Barohn RJ, Ernstoff RM, Kaminski HJ, Keesey JC, Penn AS, et al. Myasthenia gravis: recommendations for clinical research standards. Task Force of the Medical Scientific Advisory Board of the Myasthenia Gravis Foundation of America. Neurology. 2000;55(1):16-23.

22. Balduzzi SRG, Schwarzer G. How to perform a meta-analysis with R: a practical tutorial. Evid Based Ment Health. 2019;22:153-60.

23. Eden RD, Gall SA. Myasthenia gravis and pregnancy: a reappraisal of thymectomy. Obstet Gynecol. 1983;62(3):328-33.

24. Fraser D, Turner JW. Myasthenia gravis and pregnancy. Proc R Soc Med. 1963;56(5):379-81.

25. Shi B, Zeng L. Management of myasthenia gravis during pregnancy: a report of eight cases. Open Life Sci. 2018;13:28-33.

26. Batocchi AP, Majolini L, Evoli A, Lino MM, Minisci C, Tonali P. Course and treatment of myasthenia gravis during pregnancy. Neurology. 1999:52(3):447-52.

27. Giwa-Osagie OF, Newton JR, Larcher V. Obstetric performance of patients with my asthenia gravis. Int J Gynaecol Obstet. 1981;19(4):267-70.

28. Almeida C, Coutinho E, Moreira D, Santos E, Aguiar J. Myasthenia gravis and pregnancy: anaesthetic management-a series of cases. Eur J Anaesthesiol. 2010;27(11):985-90

29. Gilhus NE, Hong Y. Maternal myasthenia gravis represents a risk for the child through autoantibody transfer, immunosuppressive therapy and genetic influence. Eur J Neurol. 2018;25(12):1402-9.

30. Tsurane K, Tanabe S, Miyasaka N, Matsuda M, Takahara M, Ida T, et al. Management of labor and delivery in myasthenia gravis: a new protocol. J Obstet Gynaecol Res. 2019;45(5):974-80.

31. Nicholls-Dempsey L, Czuzoj-Shulman N, Abenhaim HA. Maternal and neonatal outcomes among pregnant women with myasthenia gravis. J Perinat Med. 2020;48(8):793-8.

32. Selman MH, Niks EH, Titulaer MJ, Verschuuren JJ, Wuhrer M, Deelder AM lgG fc N-glycosylation changes in Lambert-Eaton myasthenic syndrome and myasthenia gravis. J Proteome Res. 2011;10(1):143-52.

33. van de Geijn FE, Wuhrer M, Selman MH, Willemsen SP, de Man YA, Deelder AM, et al. Immunoglobulin G galactosylation and sialylation are associated with pregnancy-induced improvement of rheumatoid arthritis and the postpartum flare: results from a large prospective cohort study. Arthritis Res Ther. 2009;11(6):R193.

34. Mijakovac A, Juric J, Kohrt WM, Kristic J, Kifer D, Gavin KM, et al. Effects of estradiol on immunoglobulin G glycosylation: mapping of the downstream signaling mechanism. Front Immunol. 2021;12:680227.

35. Zhang J, Benedek G, Bodhankar S, Lapato A, Vandenbark AA, Offner H. IL-10 producing $B$ cells partially restore E2-mediated protection against EAE in PD-L1 deficient mice. J Neuroimmunol. 2015;285:129-36.

36. Jensen F, Muzzio D, Soldati R, Fest S, Zenclussen AC. Regulatory B10 cells restore pregnancy tolerance in a mouse model. Biol Reprod. 2013;89(4):90

37. Delpy L, Douin-Echinard V, Garidou L, Bruand C, Saoudi A, Guéry JC. Estrogen enhances susceptibility to experimental autoimmune myasthenia gravis by promoting type 1-polarized immune responses. J Immunol. 2005;175(8):5050-7.

38. Xu L, Dong B, Wang H, Zeng Z, Liu W, Chen N, et al. Progesterone suppresses Th17 cell responses, and enhances the development of regulatory $T$ cells, through thymic stromal lymphopoietin-dependent mechanisms in experimental gonococcal genital tract infection. Microbes Infect. 2013;15(12):796-805.
39. Davoudi V, Keyhanian K, Bove RM, Chitnis T. Immunology of neuromyelitis optica during pregnancy. Neurol Neuroimmunol Neuroinflamm. 2016:3(6):e288

40. Brenner T, Beyth Y, Abramsky O. Inhibitory effect of alpha-fetoprotein on the binding of myasthenia gravis antibody to acetylcholine receptor. Proc Natl Acad Sci USA. 1980;77(6):3635-9.

41. Wolfe GI, Kaminski HJ, Sonnett JR, Aban IB, Kuo HC, Cutter GR. Randomized trial of thymectomy in myasthenia gravis. J Thorac Dis. 2016:8(12):E1782-3.

42. Li H, Ruan Z, Gao F, Zhou H, Guo R, Sun C, et al. Thymectomy and risk of generalization in patients with ocular myasthenia gravis: a multicenter retrospective cohort study. Neurotherapeutics. 2021;18:2449-57.

43. Narayanaswami P, Sanders DB, Wolfe G, Benatar M, Cea G, Evoli A, et al. International consensus guidance for management of myasthenia gravis: 2020 update. Neurology. 2021;96(3):114-22.

44. Matthews I, Sims G, Ledwidge S, Stott D, Beeson D, Willcox N, et al. Antibodies to acetylcholine receptor in parous women with myasthenia: evidence for immunization by fetal antigen. Lab Investig. 2002;82(10):1407-17

\section{Publisher's Note}

Springer Nature remains neutral with regard to jurisdictional claims in published maps and institutional affiliations.
Ready to submit your research? Choose BMC and benefit from:

- fast, convenient online submission

- thorough peer review by experienced researchers in your field

- rapid publication on acceptance

- support for research data, including large and complex data types

- gold Open Access which fosters wider collaboration and increased citations

- maximum visibility for your research: over $100 \mathrm{M}$ website views per year

At BMC, research is always in progress.

Learn more biomedcentral.com/submissions 